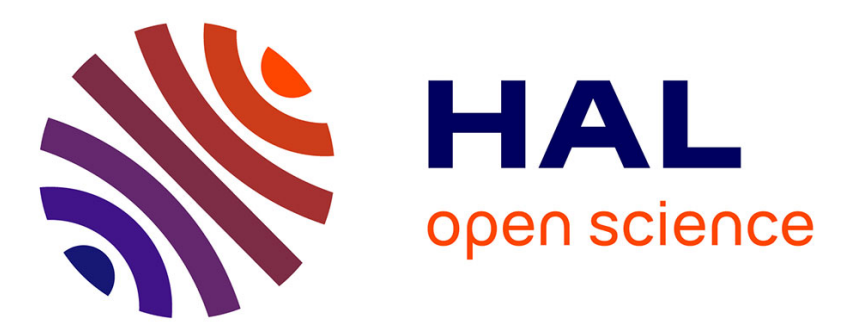

\title{
Investigation of processing effects on the corrosion resistance of Ti20Mo alloy in saline solutions
}

G. Bolat, J. Izquierdo, T. Gloriant, R. Chelariu, D. Mareci, R. M Souto

\section{To cite this version:}

G. Bolat, J. Izquierdo, T. Gloriant, R. Chelariu, D. Mareci, et al.. Investigation of processing effects on the corrosion resistance of Ti20Mo alloy in saline solutions. Corrosion Science, 2015, 98, pp.170-179. 10.1016/j.corsci.2015.05.025 . hal-01160141

HAL Id: hal-01160141

https://hal-univ-rennes1.archives-ouvertes.fr/hal-01160141

Submitted on 15 Sep 2015

HAL is a multi-disciplinary open access archive for the deposit and dissemination of scientific research documents, whether they are published or not. The documents may come from teaching and research institutions in France or abroad, or from public or private research centers.
L'archive ouverte pluridisciplinaire HAL, est destinée au dépôt et à la diffusion de documents scientifiques de niveau recherche, publiés ou non, émanant des établissements d'enseignement et de recherche français ou étrangers, des laboratoires publics ou privés. 


\title{
Investigation of processing effects on the corrosion resistance of Ti20Mo alloy in saline solutions
}

\author{
G. Bolat ${ }^{1}$, J. Izquierdo ${ }^{2}$, T. Gloriant ${ }^{3}$, R. Chelariu ${ }^{4}$, D. Mareci ${ }^{1}$, R.M. Souto ${ }^{2,5}$
}

${ }^{1}$ The "Gheorghe Asachi” Technical University of Iasi, Faculty of Chemical Engineering and Environmental Protection, 73 Prof. dr. doc. D. Mangeron St., 700050, Iasi, Romania

2 Department of Chemistry, University of La Laguna, P.O. Box 456, E-38200 La Laguna, Tenerife, Canary Islands, Spain

${ }^{3}$ INSA Rennes, UMR CNRS 6226 Institut des Sciences Chimiques de Rennes / Chimie Métallurgie, 20 avenue des Buttes de Coësmes, 35043 Rennes Cedex, France

4 The "Gheorghe Asachi" Technical University of Iasi, Faculty of Materials Science and Engineering, 41 Prof. dr. doc. D. Mangeron St., 700050, Iasi, Romania

${ }^{5}$ Instituto Universitario de Materiales y Nanotecnologías, University of La Laguna, P.O. Box 456, E-38200 La Laguna, Tenerife, Canary Islands, Spain

Corresponding Authors: Ricardo M. Souto, University of La Laguna, Department of Chemistry, P.O. Box 456, 38200 La Laguna (Tenerife), Spain. Phone: +34922318067, Fax: +34922318005, E-mail: rsouto@ull.es

Daniel Mareci, "Gheorghe Asachi” Technical University of Iasi, Faculty of Chemical Engineering and Environmental Protection, 73 Prof. Dr. Doc. D. Mangeron St., 700050, Iasi, Romania. E-mail: danmareci@yahoo.com 


\begin{abstract}
The electrochemical properties of Ti20Mo alloys prepared using different fabrication procedures, namely cold crucible levitation melting (CCLM) and powder sintering, were investigated using linear potentiodynamic polarization and EIS measurements. The surface condition was established using AFM, with the observation of a more porous surface finish in the case of powder sintering. A major effect of surface conditioning on the corrosion resistance of Ti20Mo alloys was observed, where the compact finish exhibits a superior corrosion resistance in chloride-containing saline solutions. Less insulating surfaces towards electron exchange resulted for the more porous finish as revealed by scanning electrochemical microscopy (SECM).
\end{abstract}

Keywords: A. Alloy; A. Titanium; B. AFM; B. EIS; B. Polarization; C. Passivity. 


\section{Introduction}

Metallic biomaterials present a high potential for biomedical applications, due to their excellent mechanical strength that is outstanding in comparison with polymers or ceramics. Standard metallic biomaterials include stainless steels, cobalt-based and titanium-based alloys. Ti-based alloys are generally preferred to stainless steels and cobalt-based alloys because of their properties: high corrosion resistance, biocompatibility and adequate mechanical properties [1]. Their remarkable corrosion resistance is due to the passive oxide layer formed on the surface of titanium in air or in most aqueous solutions. The electrochemical properties of the oxide layer constitute a key factor for biocompatibility of titanium and its alloys. Commercially pure titanium (Cp-Ti) and Ti6A14V alloy are currently the most widely used metallic materials in biomedical applications. However, the release of $\mathrm{V}$ and $\mathrm{Al}$ ions to the human body causes long-term adverse reaction with body tissues [2]. Thus, new Ti-based alloys containing non-toxic elements $(\mathrm{Nb}, \mathrm{Ta}, \mathrm{Zr}, \mathrm{Mo}, \mathrm{Sn})$ are of special interest for the biomedical field. Among them, Mo participates in the regulation of the $\mathrm{pH}$ balance in the body [3]. Moreover, alloying titanium with Mo $\beta$-stabilizers improves the corrosion resistance [410], in addition to adequate mechanical compatibility and good cytocompatibility [11-16] despite one controversial report [17]. Unfortunately, titanium and molybdenum are difficult to alloy through a conventional melting-casting process due to the big difference in melting point and specific gravity between the two metals. New fabrication procedures were thus developed, particularly powder sintering [10,18-20] and cold crucible levitation melting [21] are efficient methods for the synthesis of Ti-Mo alloys in a wide range of compositions. Though similar composition ranges are achieved with the two kinds of 
procedures, their fabrication procedures are significantly different and produce materials with variations in the microstructure as revealed by the major difference in porosity that is observed. Due to its more porous structure, sintered alloys exhibit a decrease in the elastic modulus of solid materials [10,22], which is often claimed to be benefitial for biomaterial application because porous structures promote tissue in-growth [23,24]. More porous surfaces can also be produced by means of surface processing techniques, in an attempt to enhance biocompatibility [16].

The purpose of this study was to investigate the effect of alloy fabrication procedures on the corrosion resistance of Ti20Mo alloys, by considering samples fabricated using cold crucible levitation melting (CCLM) and powder sintering, respectively. Two different surface conditions with major changes in surface roughness were thus produced. Since chloride ions are known to promote instabilities and eventual local breakdown of the protecting passive layers formed on Ti-based biomaterials [2529], a saline solution was chosen as the test environment. Conventional electrochemical and scanning electrochemical techniques were employed to evaluate the stability and reactivity of the protective oxide layers formed on the surface of the alloys.

\section{Materials and methods}

\subsection{Materials}

Experiments were carried out on two Ti20Mo alloys (20 wt.\% of Mo) with different surface finish (compact and porous). The compact Ti20Mo alloy was synthesized by the cold crucible levitation melting (CCLM) technique following the 
procedure described before [21]. It involved the use of an induction furnace (Fives Celes, Lautenbach, France) operating under a pure Ar atmosphere, which was introduced after several cycles of high vacuum pumping, was employed. After solidification, the alloy was heat treated at $950{ }^{\circ} \mathrm{C}$ for 20 hours (annealed in the $\beta$-phase domain) in order to homogenize the microstructure due to the thermal gradient occurring during solidification, and then water quenched. The ingots were cold rolled to $90 \%$ in thickness and machined to obtain the test samples. After this mechanical treatment, the samples were solution treated at $850{ }^{\circ} \mathrm{C}$ for 30 minutes and water quenched. The aim of this treatment was to restore a fully recrystallized metastable $\beta$ microstructure from the coldrolled state. The test samples in the form of rods were cut into disks of $0.28 \mathrm{~cm}^{2}$ circular area. They were ground with $\mathrm{SiC}$ abrasive paper up to 2000 grit, followed by a final polishing stage using $1 \mu \mathrm{m}$ alumina suspension. The polished samples were degreased with ethyl alcohol, ultrasonically cleaned in deionized water, and finally dried under air stream.

The porous Ti20Mo alloy has been synthesized following the powder sintering procedure described elsewhere [16]. In brief, metal powders of Ti and Mo were dry mixed and compacted in cylinders by cold uniaxial compacting under a pressure of 400 MPa. Sintering was carried out under a high purity argon atmosphere. Samples were sintered at $1350{ }^{\circ} \mathrm{C}$ for $48 \mathrm{~h}$ in a medium frequency induction vertical furnace and naturally cooled.

\subsection{Electrochemical tests}


The alloy samples were placed in a glass corrosion flow cell kit $(\mathrm{C} 145 / 170$, Radiometer, France), which was filled with naturally-aerated saline solution [30]. The tests were conducted in three saline solutions with 1,2 and $3 \mathrm{wt} . \% \mathrm{NaCl}$. The $\mathrm{pH}$ of the three saline solutions was 6.9. A saturated calomel electrode was used as the reference electrode, and a platinum coil as the counter electrode. The potentials in this paper are reported versus the saturated calomel electrode (SCE). Measurements were performed at room temperature $\left(22 \pm 3{ }^{\circ} \mathrm{C}\right)$.

Conventional electrochemical measurements were performed using a potentiostat Model PARSTAT 4000 (AMETEK, Berwyn, PA, USA). The instrument was controlled by a personal computer using VersaStudio software. The electrochemical impedance was measured before performing the potentiodynamic polarization test. Electrochemical impedance spectroscopy (EIS) and potentiodynamic polarization and methods were employed to characterize the corrosion behaviour of the Ti20Mo alloy surface preparations. The alternating current $(\mathrm{AC})$ impedance spectra were obtained with a scan frequency ranging from $100 \mathrm{kHz}$ to $1 \mathrm{mHz}$ with an amplitude of $10 \mathrm{mV}$. The electrochemical impedance spectra were obtained at different times ( 1 hour and 1 day) after the electrode was immersed in the saline solution. The EIS experimental data were analyzed in terms of equivalent circuits (EC) using ZSimpWin 3.22 software (AMETEK, Berwyn, PA, USA). Potentiodynamic measurements were also carried out in all three saline solutions at room temperature using the same potentiostat. These measurements were conducted by stepping the potential using a scanning rate of $1 \mathrm{mV} \mathrm{s}^{-1}$ from -1.0 to $+1.0 \mathrm{~V}_{\mathrm{SCE}}$. 
A high-resolution SECM equipment supplied by Sensolytics (Bochum, Germany), was employed for spatially-resolved characterization of the electrochemical reactivity of the compact and porous Ti20Mo alloys. The instrument was built around a PalmSens electrochemical interface (Utrecht, The Netherlands), all controlled with a personal computer. The alloy samples were either tested at their open circuit potentials in the test solutions, or polarized using the bipotentiostat built in the electrochemical interface. The specimens were mounted horizontally facing upwards at the bottom of a cell made of polytetrafluoroethene, which was equipped with an $\mathrm{Ag} / \mathrm{AgCl} / \mathrm{KCl}$ (3M) reference electrode and a platinum counter electrode, all set up in. For the sake of comparison, potentials were expressed in relation to the standard calomel electrode by taking in account the potential difference between the two reference electrodes. The electrochemical cell was located inside a Faraday cage. Tip microelectrodes were made from $10 \mu \mathrm{m}$ dia. platinum wires sealed in glass. $0.5 \mathrm{mM}$ ferrocene-methanol was added to the 1 and 2 wt. $\% \mathrm{NaCl}$ solutions to act as electrochemical mediator at the tip. To enable the oxidation of the ferrocene-methanol the tip was kept at a constant potential of +0.52 $\mathrm{V}_{\mathrm{SCE}}$ [31]. The micromanipulator stand of the SECM instrument was used to hold the microelectrode in place. The establishment of the operating tip distance over the sample was performed by slowly approaching the surface of the titanium alloy sample under study with the tip and simultaneously recording the measured current at the microelectrode vs. $z$ displacement (i.e., $z$-approach curve). In our experiments the microelectrode was stopped when the measured current changed about $30 \%$ of the steady-state value in the bulk of the electrolyte. Subsequently, the tip was withdrawn 10 $\mu \mathrm{m}$ from the sample surface, and images were obtained by scanning the tip parallel to the 
sample surface (i.e., constant height operation). SECM images were obtained covering an area of $250 \mu \mathrm{m} \times 250 \mu \mathrm{m}$ using a scan rate of $25 \mu \mathrm{m} \mathrm{s}^{-1}$.

\subsection{Alloy characterization methods}

Topography and surface roughness were determined by atomic force microscopy (AFM) using a NanoSurf easyScan 2 (Nanosurf AG, Liestal, Switzerland). The instrument was equipped with silicon cantilevers and easyScope video camera. The images were recorded at a scanning rate of $0.2 \mathrm{~s}$ line $\mathrm{e}^{-1}$. Two parameters were employed to characterize the surface roughness, namely the roughness average $\left(R_{\mathrm{a}}\right)$; and the root mean square roughness $\left(R_{\mathrm{q}}\right)[32]$.

Wettability of the different surface preparations of Ti20Mo was established by contact angle measurements. They were performed using an EasyDrop instrument (Krüss GmbH, Hamburg, Germany) controlled by a personal computer using Drop Shape Analysis specific software.

The surface morphology of the Ti20Mo samples retrieved from the electrochemical cell after recording the potentiodynamic polarization tests, up to $+1.0 \mathrm{~V}$ (SCE) in 3 wt.\% $\mathrm{NaCl}$ solution, was assessed using scanning electron microscopy (SEM) using a Quanta 3D instrument (FEI, Hillsboro, OR, USA).

\section{Results and discussion}

\subsection{Surface characteristics}


Depending on the fabrication procedure employed to produce the Ti20Mo alloys, two significantly different surface finishes were obtained in this study, as characterized by major differences in surface roughness. Surface roughness was determined from the analysis of atomic force microscopy observations of the samples as given in Figure 1. A rugged surface was observed for the sintered sample, and it even displays the main direction of treatment despite the final recrystallization procedure (Fig. 1A). Conversely, a smoother surface resulted from the cold crucible melting process (Fig. 1B). Parameters regarding the surface roughness of the two samples as determined from AFM images are listed in Table 1, a quantification of the observed big differences in surface finish between the Ti20Mo alloys synthesized by each fabrication method.

The wettability of compact and porous Ti20Mo alloys was investigated by dropping distilled water on their surface and subsequently recording the corresponding contact angles at the liquid/solid interfaces. Figure 2 depicts the results of the measurements performed after the samples were maintained in $3 \mathrm{wt} . \% \mathrm{NaCl}$ solution for $24 \mathrm{~h}$. Both compact and porous surfaces of Ti20Mo alloys exhibited water contact angles $\theta>65^{\circ}$ defined as hydrophobic surfaces [33]. A higher contact angle corresponds to lower absorption, which means that the passive layer formed in aerated $3 \mathrm{wt} . \% \mathrm{NaCl}$ solution on the compact Ti20Mo alloy have a high anti-corrosion properties than passive layer of porous Ti20Mo alloy. However, it is known that the wettability can significantly influence the cell adhesion; a small contact angle propels the ingrowth of bone on the implant surface forming biological fixation $[23,24]$.

\subsection{EIS characterization}


Impedance spectra recorded for compact and porous Ti20Mo alloys in 1, 2 and 3 wt.\% $\mathrm{NaCl}$ solutions at different immersion times are displayed in Figures 3 and 4 in the form of Nyquist and Bode diagrams. For compact Ti20Mo alloy, Nyquist diagrams show that the data are distributed along a single depressed, capacitive-like semicircle which is related to the complete passive barrier layer formed on the surface of the material. Conversely, EIS data for porous Ti20Mo alloy in the Nyquist format shows the presence of two depressed, capacitive-like semicircles: one at high frequency values that is related to interface formed between the electrolyte and the porous outer layer of the surface films, and a second semicircle present at intermediate and lower frequencies related to the inner passive barrier layer. That is, the oxide film responsible for the protection of the alloy in the environment has a duplex structure with different corrosion resistance characteristics. The inner part is the main contributor to protection because the outer layer is not effectively blocking the ingress of aggressive species of the electrolytes through its pores [34].

The presence of one time constant can be described by means of an equivalent circuit (EC) with only one parallel $R Q$ combination as shown in Figure 5A. The EC consists of the parallel combination terms $\left(R_{\mathrm{bL}} Q_{\mathrm{bL}}\right)$ in series with the resistance of the solution $\left(R_{\text {sol }}\right)$ occurring between the compact Ti20Mo sample and the reference electrode. The parameters $R_{\mathrm{bL}}$ and $Q_{\mathrm{bL}}$ describe the properties of the passive layer formed on compact Ti20Mo alloy, respectively the barrier passive layer resistance $\left(R_{\mathrm{bL}}\right)$ and capacitance of the barrier layer $\left(Q_{\mathrm{bL}}\right)$. Constant phase elements (CPE, $\left.Q\right)$ were used in the EC instead of capacitors $(C)$, allowing for the effects of deviations to ideality related to electrode roughness and heterogeneities of the surface films to be considered. The $\chi^{2}$ 
value, around $0.5 \times 10^{-4}$, indicates very good agreement between the experimental and simulated data. The values of the parameters $\left(R_{\mathrm{bL}}, Q_{\mathrm{bL}}\right)$ obtained with the fitting procedure are reported in Table 2.

For the compact Ti20Mo alloy, the impedance modulus was observed to increase during the exposure of the samples to all three saline solutions. Barrier oxide layer can block the access of electrochemically active species to the electrode surface, restricting ion diffusion to the surface, and thus reducing the overall corrosion rate [35] which can explain the increase in resistance with the elapse of immersion time. A decrease of resistance of barrier layer with increase in concentration of chloride ions in the solution was also observed.

The EC proposed to model the EIS data obtained from porous Ti20Mo alloy is shown in Figure 5B. In this model $R_{\mathrm{bL}}$ is the barrier layer resistance and $Q_{\mathrm{bL}}$ is the capacitance of the inner layer exhibiting barrier characteristics. $R_{\mathrm{pL}}$ is the additional resistance of the porous layer (solution inside the pores) and $Q_{\mathrm{pL}}$ is the capacitance of the pore wall. For porous Ti20Mo alloy, the resistance of barrier layer $\left(R_{\mathrm{bL}}\right)$ values are significantly higher than the porous layer $\left(R_{\mathrm{pL}}\right)$ values by a factor of about $10 \Omega \mathrm{cm}^{2}$, demonstrating that the resistance of oxide layer is due to the barrier oxide layer. Also, the resistance of passive layer increase during the exposure in saline solutions. This indicates an improved corrosion resistance in these electrolytes. It is worth noting that the values for $R_{\mathrm{bL}}$ of the compact Ti20Mo alloy samples were about one order of magnitude higher compared to those for the porous Ti20Mo samples.

\subsection{Potentiodynamic polarization characterization}


Potentiodynamic polarization measurements were performed after 1 day immersion of the samples in the test solutions while left at their corresponding open circuit potentials. The potentiodynamic polarization curves of the compact and porous Ti20Mo alloys in saline solutions are shown in Figure 6. The curves do not exhibit a typical active-passive characteristic, then translating directly from the active region into a passive region. Additionally, in the case of compact Ti20Mo alloy given in Figure 6A, no breakdown of the passive layer occurs in the range of potential test (up to $+1.0 \mathrm{~V}_{\mathrm{SCE}}$ ). This indicates that the oxide layer formed on the surface of compact Ti20Mo alloys is integral and protective. It is well known that the corrosion resistance of a given material depends on several factors such as composition, environment and microstructure [36]. Indeed, the porous structure has an important role on the corrosion behavior. It has been reported that the porous materials are more susceptible to corrosion attack than the compact ones [37-39]. The low porosity samples (with isolated pores) are resistant to localized corrosion attack. However, the environment is an important factor influencing this type of corrosion. Thus, the porous Ti20Mo alloy in 2 and 3 wt. $\% \mathrm{NaCl}$ solution displays distinct passivation behavior, and passive layer is broken.

In general, all the polarization curves for both samples can be divided into three potential domains. The cathodic domain includes potentials where the current is determined by the oxygen reduction reaction. The second domain includes the transition from cathodic to anodic current at the corrosion potential $\left(E_{\text {cor }}\right)$. And the third domain corresponds to the passive plateau were the current density is, approximately, constant. Finally, a fourth region was characterized only for the porous Ti20Mo alloy, that is 
evidenced by the abrupt increase in current due to breakdown of the passive layer that occurred at the more positive potential values under investigation.

Tafel analysis of both the anodic and cathodic branches of the polarization curves delivered values for $E_{\mathrm{cor}}$, corrosion current densities $\left(j_{\mathrm{cor}}\right)$, and Tafel slopes $\left(\beta_{\mathrm{a}}, \beta_{\mathrm{c}}\right)$. In addition, the passive current density $\left(j_{\text {pass }}\right)$ was determined at $+0.2 \mathrm{~V}_{\mathrm{SCE}}$, as well as the breakdown potential $\left(E_{\mathrm{bd}}\right)$ in those alloys and environments were rupture of the protecting passive layer occurred within the potential range covered by the polarization curves. The corresponding corrosion parameters obtained from the polarization curves of both tested Ti20Mo alloys are listed in Table 3. For both compact and porous Ti20Mo alloys, increasing the $\mathrm{NaCl}$ concentration in solution slowly increased the corrosion current densities. It is know that corrosion resistance of titanium and its alloys is associated with the formation of the resistant titanium oxide layer on their surface. The corrosion current density of the porous Ti20Mo alloy samples were about 25-30 times higher compared to the compact samples. Therefore, the porous Ti20Mo alloy was quantitatively more susceptible to corrosion than the compact Ti20Mo alloy due to their larger true surface area exposed to the electrolyte.

The dependence of passive current density of TiMo alloy on the concentration of $\mathrm{NaCl}$ in the solution is presented in Table 3. An increase in passive current density with increase in concentration of chloride ions in the solution was observed. Next, the average current densities measured in the passive regime are smaller for the compact Ti20Mo alloy compared to porous Ti20Mo alloy.

The surface topography of the compact and porous Ti20Mo alloys samples polarized up to $+1.0 \mathrm{~V}_{\mathrm{SCE}}$ in 3 wt. $\% \mathrm{NaCl}$ solution were examined by scanning electron 
microscopy (SEM) and are displayed in Figure 7. They revealed that uniform oxidation occurred on the compact Ti20Mo alloy during the corrosion test in the chloridecontaining solution, and did not show visible signs of deterioration (Figure 7A). Conversely, in the case of porous Ti20Mo alloy, a major distribution of corrosion pits randomly distributed on the surface was observed, evidences of local breakdown of the protective oxide layer that was unable to resist the aggressive action of chloride ions (Figure 7B). Indeed, the porous TiMo alloy could only show some degree of resistance against breakdown of the oxide layer during polarization up to $+1.0 \mathrm{~V}_{\mathrm{SCE}}$ when exposed to the 1 wt. $\% \mathrm{NaCl}$ solution.

\subsection{Scanning microelectrochemical microscoopy characterization}

Electrochemical reactivity towards electron exchange of the materials was characterized by SECM operated in the feedback mode. This was done by scanning the measuring tip parallel to the surface at ca. $10 \mu \mathrm{m}$ distance in 1 and 2 wt. $\% \mathrm{NaCl}$ solutions, in order to analyze the influence of the chloride anions. Figure 8 depicts the maps obtained with the compact Ti20Mo specimen while left unbiased or subjected to various constant potential polarization as to evidence the effect of the electrical condition of the material on the surface reactivity. Analogously, Figure 9 displays the corresponding surface reactivity images recorded for the porous material.

Clear differences can be encountered for the compact metal after increasing the salt concentration. Notice that the same colour scale has been selected for displaying each couple of scans taken using the same surface electrical conditions, in order to facilitate the comparison. For the images recorded at both their corresponding spontaneous OCP 
conditions and under $-0.18 \mathrm{~V}_{\mathrm{SCE}}$ polarization, positive feedback effects are better observed when immersed in the 2 wt. $\% \mathrm{NaCl}$ solution. That is, normalized tip currents greater than unity were measured in the right column of Figures $8 \mathrm{~A}-\mathrm{B}$, an indication of the availability of certain regions of the sample to undergo electron exchange, thus producing ferrocene-methanol regeneration at those locations. This feature does not easily occur when a similar specimen was exposed to 1 wt.\% $\mathrm{NaCl}$, evidencing a minimum salt content is required to promote deterioration of the insulating characteristics of the protective oxide layer formed on the surface of the material, as to eventually allow the electron transfer to occur. For this reason, mostly negative feedback effects are recorded, resulting from the blockage of the diffusion of the electroactive species towards the tip when it approaches the sample, as observed in the left column of Figures 8A-B.

Figure $8 \mathrm{C}$ shows significantly smaller tip currents than those observed in the previous scans. Since this substrate potential is, from a thermodynamic point of view, enough to partially oxidize the redox mediator, the current decrease is an indication of the establishment of a competition process between the tip and the substrate to become the reacting sites for the oxidation of ferrocene-methanol. When the lowest salt content considered here is used (see left column of Figure $8 \mathrm{C}$ ), the competitive behaviour appears to evolve with time during the period of time required to complete the scan acquisition. This scan was initiated from the lowest position of the $Y$ axis, and doing sequential linear scan in the $X$ axis, thus finishing at the highest $Y$ coordinates. As readily observable in the figure, the initial linear scans of the map correspond with those lines displaying the highest tip current values. This current decreases progressively with the elapse of time and the acquisition of the scan along the $Y$ axis. This time effect is much faster than the 
scan acquisition itself, that is, spatial differences cannot be resolved due to a highly dynamic process taking place on the substrate. This observation indicates that the sample is becoming more conductive with time while polarized at this potential, leading to a more pronounced competitive behaviour. Partial degradation of the passive layer should thus be occurring at these initial stages. Conversely, this competition is more pronounced in the $2 \mathrm{wt} . \% \mathrm{NaCl}$ solution without evidencing a time dependence this time, since the whole scanned area given in the right column of Figure $8 \mathrm{C}$ presents, from the very beginning, a heterogeneously spatially-resolved distribution of normalized currents below 0.3 , much smaller than those encountered before.

More conductive characteristics were found when analysing the porous Ti20Mo alloy. Indeed, Figures 9A-B show maximum tip currents higher than those registered in Figures 8A-B, respectively, resulting from stronger positive feedback effect. Additionally, in general terms it can be deduced, from Figure 9C, that competitive behaviour and subsequent current decay is more pronounced in the porous samples rather than the compact specimens when positively polarized. Again the increment in chloride concentration produces these effects to be enhanced, though in this case the presence of singularities can be clearly found when samples are immersed in 2 wt.\% $\mathrm{NaCl}$ and anodically biased at potential values over $-0.18 \mathrm{~V}_{\mathrm{SCE}}$. Such singularities can be seen at the right side of Figures 9B-C, plotted in this case at their own best contrasted colour scale. When the sample is biased at $-0.18 \mathrm{~V}_{\mathrm{SCE}}$, the tip current increment detected at those sites reaches values as high as three times those encountered in bulk solution. This phenomenon can only be ascribed to a positive feedback effect, which preferentially takes place at those more active sites. The needed electron transfer for this observation is 
locally favoured, probably due to local weakening of the passive layer at the pores, in addition to the larger volume available for the diffusion of the electroactive species towards the tip. From the scans, it is clear that $1 \mathrm{wt} . \% \mathrm{NaCl}$ medium is not aggressive enough to promote the required local degradation for this highly localized phenomenon to occur, though the heterogeneity of the surface is evidenced with the scan given in the left column of Figure 9B. The above mentioned sites are preferential areas for pitting corrosion, though according to the cyclic polarization curve given in Figure 6B, this anodic overpotential is too low to promote stable pit breakdown of the surface even in 3 wt. $\% \mathrm{NaCl}$. Therefore, only some pores become activated at such low polarization, and though they become pit nucleation sites, their growth is not sufficiently fast to be observed in the polarization curves that averages the current flowing over the complete exposed surface.

Finally, the singularity observed when the porous sample was polarized at +0.22 $\mathrm{V}_{\mathrm{SCE}}$ in 2 wt.\% $\mathrm{NaCl}$ (cf. right column of Figure 9C) rather close to the pitting potential but still lower, cannot be discussed in terms of positive feedback effect. No regeneration of the redox mediator is expected at this substrate potential, not even in a localized manner, and only slight competitive behaviour may happen through partial consumption of ferrocene-methanol. Since current alterations account, not only to the electron transfer phenomena, but also to the topography of the substrate, the occurrence of partial negative feedback must be the reason for this current distribution. That is, the proximity of the substrate partially blocks the diffusion of the redox mediator towards the UME and subsequently the tip current, yet this cannot occur at those region where a sufficiently large porous is present, and current may reach values close to those determined in bulk 
solution. These porous could not be easily observed in Figure 9A, with sample left at the OCP conditions, since most of the scanned area is heterogeneously promoting the regeneration of the ferrocene-methanol. Though, the adequate selection of the sample potential enables their imaging and discussion of their properties, as demonstrated in this contribution. On the other hand, the heterogeneity of the sample is still evident when sample is immersed in $1 \mathrm{wt} . \% \mathrm{NaCl}$ solution (cf. left side on Figure 9C), yet not as high currents are encountered over the porous. This may be simply related to the porous size randomly distributed and encountered, though an eventual onset of corrosion process at 2 wt.\% $\mathrm{NaCl}$ and subsequent reaction at the tip of any species generated at the sample cannot be discarded at this stage.

\section{Conclusions}

The effect of alloy fabrication technique and surface finish on the corrosion resistance of Ti20Mo alloy was studied in saline solutions of various chloride concentrations. The following observations were made:

(1) The presence of chloride ions in solutions had a negative influence on the corrosion behaviour of both compact (CCLM) and porous (sintered) Ti20Mo alloys. With the decrease the concentration of chloride ions the corrosion potential moves towards positive direction and the corrosion and passive current densities reduces, indicating an improvement in corrosion resistance. The EIS results indicate that two-layer surface film is produced on the porous alloy. 
(2) The compact Ti20Mo alloy is effectively pitting corrosion resistant and showed lower susceptibility to chloride corrosion. Porosity had a negative influence on the corrosion behavior of Ti20Mo alloy. Thus, some concern must be taken not to select a certain surface preparation method for a given biomaterial exclusively based on better biological behaviour (such as smaller contact angles or greater porosity for enhanced biofixation). Changes in their electrochemical behaviour may also occur, eventually operating in the opposite direction as it has been shown for Ti20Mo alloys, thus compromising their chemical stability.

(3) Localized breakdown mainly occurs at the pores formed on the rugged surface of the porous specimen, and the passive layer is broken at them even at potential values well below the average pit potential. Scanning electrochemical microscopy observations thus facilitate a more clear understanding of the effect of pores in the degradation characteristics of the passive oxide layers formed on the materials when chloride ions are present in the environment.

\section{Acknowledgments}

This work was supported by Romanian National Authority for Scientific Research (CNCS-UEFISCDI, project No. PN-II-ID-PCE-2011-3-0218), and by the Spanish Ministry of Economy and Competitiveness (MINECO, Madrid, Spain) and the European Regional Development Fund (project No. CTQ2012-36787). A Research Training Grant awarded to J.I. by the Spanish Ministry of Science and Innovation (Programa de Formación de Personal Investigador) is appreciated. 


\section{References}

[1] M. Geetha, A.K. Singh, R. Asokamani, A.K. Gogia, Ti based biomaterials, the ultimate choice for orthopaedic implants-A review, Prog. Mater. Sci. 54 (2009) $397-425$.

[2] M. Niinomi, Recent research and development in titanium alloys for biomedical applications and healthcare goods. Sci. Technol, Adv. Mater. 4 (2003) 445-454.

[3] K.V. Rajagopalan, Molybdenum: an essential trace element in human nutrition, Annu. Rev. Nutr. 8 (1988) 401-527.

[4] M.C.R. Alvez Rezende, A.P. Rosifini Alvez, E.N. Codaro, C.A. Matsumoto Dutra, Effect of commercial mouthwashes on the corrosion resistance of $\mathrm{Ti}-10 \mathrm{Mo}$ experimental alloy, J. Mater. Sci. Mater. Med. 18 (2007) 149-154.

[5] N.T.C. Oliveira, A.C. Gustaldi, Electrochemical behavior of Ti-Mo alloys applied as biomaterial, Corros. Sci. 50 (2008) 938-945.

[6] N.T.C. Oliveira, A.C. Gustaldi, Electrochemical stability and corrosion resistance of Ti-Mo alloys for biomedical applications, Acta Biomater. 51 (2009) 399-405.

[7] D. Mareci, R. Chelariu, I. Dan, D.M. Gordin, T. Gloriant, Corrosion behaviour of Ti20Mo alloy in artificial saliva, J. Mater. Sci. Mater. Med. 21 (2010) 2907-2913.

[8] D. Mareci, R. Chelariu, D.M. Gordin, M. Romas, D. Sutiman, T. Gloriant, Effect of Mo content on electrochemical behaviour of TiMo alloys for dental applications, Mater. Corros. 61 (2010) 829-837.

[9] G. Bolat, D. Mareci, R. Chelariu, J. Izquierdo, S. Gonzalez, R.M. Souto, Investigation of the electrochemical behavior of TiMo alloys in simulated physiological solutions, Electrochim. Acta 113 (2013) 470-480. 
[10] F.X. Xie, X.B. He, S.L. Cao, X. Lu, X.H. Qu, Structural characterization and electrochemical behavior of a laser-sintered Ti-10Mo alloy, Corros. Sci. 67 (2013) 217-224.

[11]R. Chelariu, G. Bolat, J. Izquierdo, D. Mareci, D.M. Gordin, T. Gloriant, R.M. Souto, Metastable beta Ti-Nb-Mo alloys with improved corrosion resistance in saline solution, Electrochim. Acta 137 (2014) 280-289.

[12]W.F. Ho, C.P. Ju, J.H. Chern Lin, Structure and properties of cast Ti-Mo alloys, Biomater. 20 (1999) 2115-2122.

[13]L. Trentania, F. Pelilloa, F.C. Pavesia, L. Ceciliania, G. Cettab, A. Forlino, Evaluation of the TiMo12Zr6Fe2 alloy for orthopaedic implants: In vitro biocompatibility study by using primary human fibroblasts and osteoblasts, Biomater. 23 (2002) 2863-2869.

[14]D.M. Gordin, T.M. Gloriant, G. Texier, I. Thibon, D. Ansel, J.L. Duval, M.D. Nagel, Development of $\beta$-type Ti-12Mo-5Ta alloy for biomedical applications: Cytocompatibility and metallurgical aspects, J. Mater. Sci.: Mater. Med. 15 (2004) $885-891$

[15]S. Nag, R. Banerjee, H.L. Fraser, Microstructural evolution and strengthening mechanisms in Ti-Nb-Zr-Ta. Ti-Mo-Zr-Fe and Ti-15Mo biocompatible alloys, Mater. Sci. Eng. C25 (2005) 357-362.

[16]E. Delvat, D.M. Gordin, T. Gloriant, J.L. Duval, M.D. Nagel, Microstructure, mechanical properties and cytocompatibility of stable beta Ti-Mo-Ta sintered alloys, J. Mech. Behav. Biomed. 1 (2008) 345-351. 
[17]E. Eisenbarth, D. Velten, M. Müller, R. Thull, J. Breme, Biocompatibility of betastabilizing elements of titanium alloys, Biomater. 25 (2004) 5705-5713.

[18]Y.H. Li, L.J. Rong, Y.Y. Li, Pore characteristics of porous NiTi alloy fabricated by combustion synthesis, J. Alloys Compd. 325 (2001) 259-262.

[19]I.H. Oh, N. Nomura, N. Masabashi, S. Hanada, Mechanical properties of porous titanium compacts prepared by poweder sintering, Scripta Mater. 49 (2003) 1197 1202.

[20]Z. Esen, S. Bor, Characterization of Ti-6Al-4V alloy foams synthesized by space holder technique, Mater. Sci. Eng. 528 (2011) 3200-3209.

[21]D.-M. Gordin, E. Delvat, R. Chelariu, G. Ungureanu, M. Besse, D. Laillé, T. Gloriant, Characterization of Ti-Ta alloys synthesized by cold crucible levitation melting, Adv. Eng. Mater. 8 (2008) 714-719.

[22]G. Ryan, A. Pandit, D.P. Apatsidis, Fabrication methods of porous metals for use in orthopaedic applications, Biomater. 27 (2006) 2651-2670.

[23] A. Bansiddhi, T.D. Sargeant, S.I. Stupp, D.C. Dunand, Porous NiTi for bone implants: A review, Acta Biomater. 4 (2008) 773-782.

[24] A.C. Jones, C.H. Arns, D.W. Hutmacher, B.K. Milthorpe, A.P. Sheppard, M.A. Kanckstedt, The correlation of pore morphology, interconnectivity and physical properties of 3D ceramic scaffolds with bone ingrowth, Biomater. 30 (2009) 14401451.

[25] R.W. Schutz, D.E. Thomas, Corrosion of titanium and titanium alloys MetalsHandbook, vol. 13, 9th ed., ASM International, Metals Park, OH, 1987, pp. 669. 
[26] G.T. Burstein, R.M. Souto, Observations of localized instability of passive titanium in chloride solution, Electrochim. Acta 40 (1995) 1881-1888.

[27] R.M. Souto, G.T. Burstein, A preliminary investigation into the microscopic depassivation of passive titanium implant materials in vitro, J. Mater. Sci: Mater. Med. 7 (1996) 337-343.

[28] G.T. Burstein, C. Liu, R.M. Souto, The effect of temperature on the nucleation of corrosion pits on titanium in Ringer's physiological solution, Biomater. 26 (2005) 245-256.

[29] G.T. Burstein, M. Carboneras, B.T. Daymond, The temperature dependence of passivity breakdown on a titanium alloy determined by cyclic noise thermammetry, Electrochim. Acta 55 (2010) 7860-7866.

[30] D. Mareci, I. Rusu, R. Chelariu, G. Bolat, C. Munteanu, D. Sutiman, R.M. Souto, Application of dynamic electrochemical impedance spectroscopy to the evaluation of the corrosion resistance of a historic bronze object in artificial acid rainwater, Eur. J. Sci. Theol. 9 (2013) 189-199.

[31]G. Ciurescu, J. Izquierdo, J.J. Santana, D. Mareci, D. Sutiman, S. González, R.M. Souto, Characterization of the localized surface chemical activity of Ti-Mo and TiTa alloys for biomedical applications using scanning electrochemical microscopy. Int. J. Electrochem. Sci. 7 (2012) 7404-7424.

[32]R.R.L. De Oliveira, D.A.C. Albuquerque, T.G.S. Cruz, F.M. Yamaji, F.L. Leite, Measurement of the nanoscale roughness by atomic force microscopy: Basic principles and applications, in: V. Bellitto (Ed.), Atomic Force Microscopy - 
Imaging, Measuring and Manipulating Surfaces at the Atomic Scale, InTech, Rijeka, 2012, pp. 147-174.

[33]E.A. Vogler, Structure and reactivity of water at biomaterial surfaces, Adv. Colloid Interface Sci. 74 (1998) 69-117.

[34]F. Mansfeld, Analysis and interpretation of EIS data for metals and alloys, Technical Report 26, Solartron-Schlumberger, Farnborough, 1993, Ch. 4.

[35] C. Gabrielli, Identification of electrochemical processes by frequency response analyisis, Techical Report 004/83, Solartron-Schlumberger, Farnborough, 1983.

[36] M. Geetha, U.M. Kamachi, A.K. Gogia, R. Asokamani, R. Baldev, Influence of microstructure and alloying elements on corrosion behaviour of $\mathrm{Ti}-13 \mathrm{Nb}-13 \mathrm{Zr}$ alloy, Corros. Sci. 46 (2004) 877-892.

[37] D.J. Blackwood, A.W.C. Chua, K.H.W. Seah, R. Thampuran, S.H. Teoh, Corrosion behaviour of porous titanium-graphite composites designed for surgical implants, Corros. Sci. 42 (2000) 481-503.

[38] K.H.W. Seah, T. Thampuran, S.H. Teoh, The influence of pore morphology on corrosion, Corros. Sci. 40 (1998) 547-556.

[39] Y.H. Li, G.B. Rao, L.J. Rong, Y.Y. Li, The influence of porosity on corrosion characteristics of porous NiTi alloy in simulated body fluid, Mater. Lett. 57 (2002) $448-451$. 


\section{Table legends}

\section{Table 1}

Surface roughness and contact angle values of the Ti20Mo alloys obtained by different processing techniques.

\section{Table 2}

Values of fitted parameters of the equivalent circuit as function of immersion time of both compact and porous Ti20Mo alloys in saline solutions. AC polarization was applied around their corresponding open circuit potential values in the aerated saline solutions.

\section{Table 3}

Electrochemical parameters (average value and (standard deviation)) determined from the polarization curves measured for both compact and porous Ti20Mo samples after 1 day immersion in the aerated saline solutions. 


\section{Figure legends}

\section{Figure 1}

AFM surface topography of (A) compact, and (B) porous Ti20Mo alloys. The images represent an $8.5 \mu \mathrm{m} \times 8.5 \mu \mathrm{m}$ area.

\section{Figure 2}

Shape of liquid drop on (A) compact, and (B) porous Ti20Mo alloys after 1 day exposure to aerated $3 \mathrm{wt} . \% \mathrm{NaCl}$ solution.

\section{Figure 3}

Measured impedance spectra for compact Ti20Mo alloy recorded at its open circuit potential during exposure to aerated saline solution, at different immersion times: $(A, B) 1$ hour, and (C,D) 1 day. Spectra are presented as $(\mathrm{A}, \mathrm{C})$ Nyquist, and $(\mathrm{B}, \mathrm{D})$ Bode diagrams.

\section{Figure 4}

Measured impedance spectra for porous Ti20Mo alloy recorded at its open circuit potential during exposure to aerated saline solution, at different immersion times: (A,B) 1 hour, and (C,D) 1 day. Spectra are presented as $(A, C)$ Nyquist, and (B,D) Bode diagrams.

\section{Figure 5}

Equivalent circuits (EC) used to fit the impedance data.

\section{Figure 6}

Linear potentiodynamic polarization curves for: (A) compact Ti20Mo and (B) porous Ti20Mo samples after 1day immersion in aerated saline solution. Scan rate: $1 \mathrm{mV} \mathrm{s}^{-1}$.

\section{Figure 7}

SEM photographs of the: (A) compact Ti20Mo and, (B) porous Ti20Mo alloy samples retrieved from 3 wt.\% $\mathrm{NaCl}$ solution after recording the potentiodynamic polarization curves. 


\section{Figure 8}

SECM images obtained over a compact Ti20Mo sample while immersed in (A,C,E) 1 wt.\% and (B,D,F) 2 wt.\% NaCl solution containing $0.5 \mathrm{mM}$ ferrocene-methanol. Sample maintained at $(\mathrm{A}, \mathrm{B})$ the spontaneous OCP, (C,D) -0.18 , and (E,F) $+0.22 \mathrm{~V}_{\mathrm{SCE}} i / i_{\mathrm{lim}}$ is the dimensionless tip current. Tip potential: $+0.52 \mathrm{~V}_{\mathrm{SCE}}$. Scan rate: $25 \mu \mathrm{m} \mathrm{s}$. The images represent a $250 \mu \mathrm{m}$ x $250 \mu \mathrm{m}$ area.

\section{Figure 9}

SECM images obtained over a porous Ti20Mo sample while immersed in (A,C,E) 1 wt.\% and (B,D,F) 2 wt.\% $\mathrm{NaCl}$ solution containing $0.5 \mathrm{mM}$ ferrocene-methanol. Sample maintained at (A,B) the spontaneous OCP, (C,D) -0.18 , and (E,F) $+0.22 \mathrm{~V}_{\mathrm{SCE}} . i / i_{\text {lim }}$ is the dimensionless tip current. Tip potential: $+0.52 \mathrm{~V}_{\mathrm{SCE}}$. Scan rate: $25 \mu \mathrm{m} \mathrm{s}^{-1}$. The images represent a $250 \mu \mathrm{m} \times 250 \mu \mathrm{m}$ area. 


\section{Highlights} resistance.

$\bullet$ sintering. oxide film.

Alloy fabrication method affects both surface finish and corrosion More porous surface finish and higher wettability produced by powder Passive layer formed on sintered alloy breaks down in saline solution. Increase in surface porosity facilitated electron transfer through the $\bullet$

More corrosion resistant alloy produced by cold crucible levitation melting. 


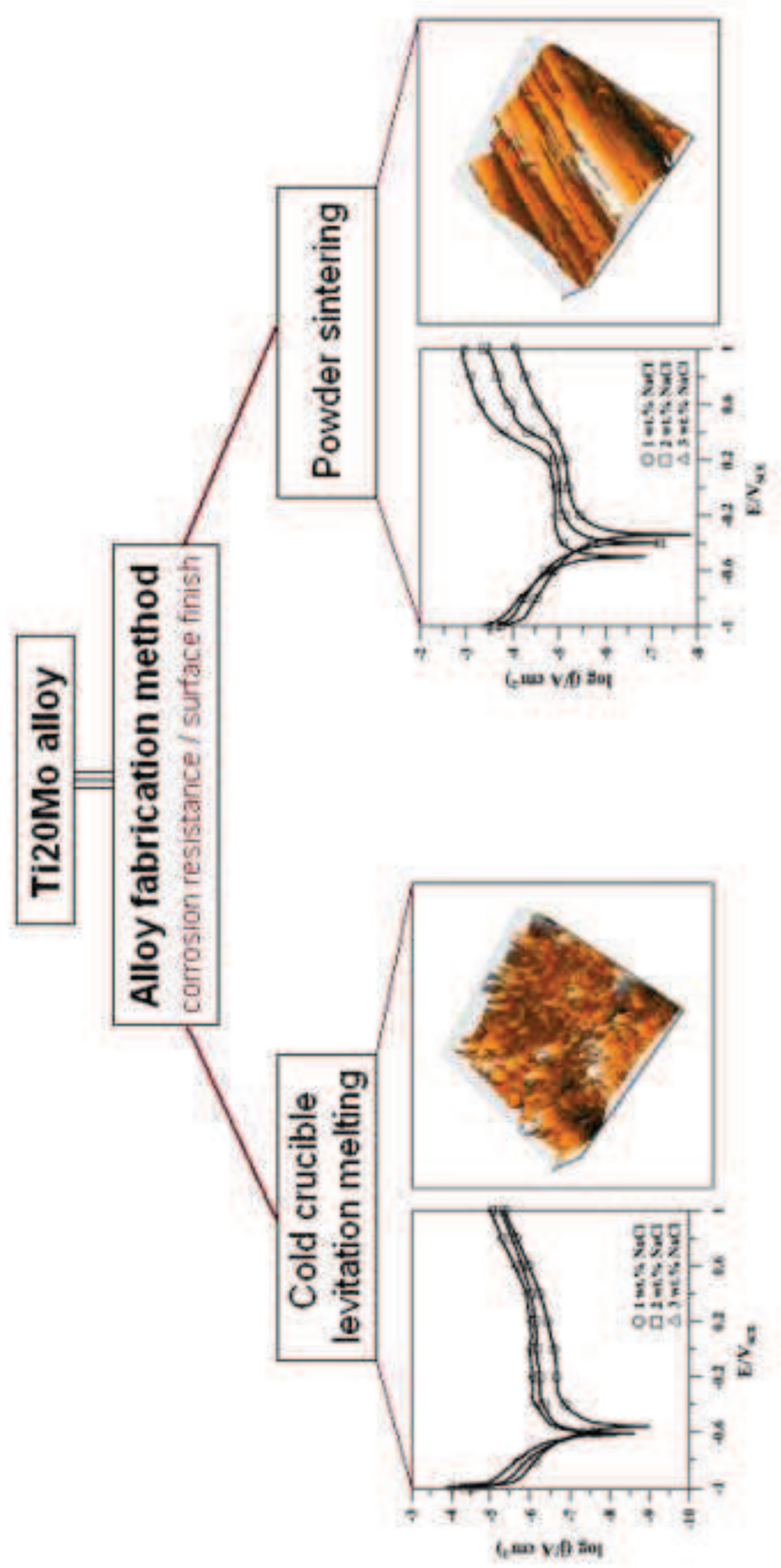

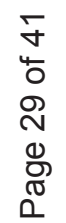




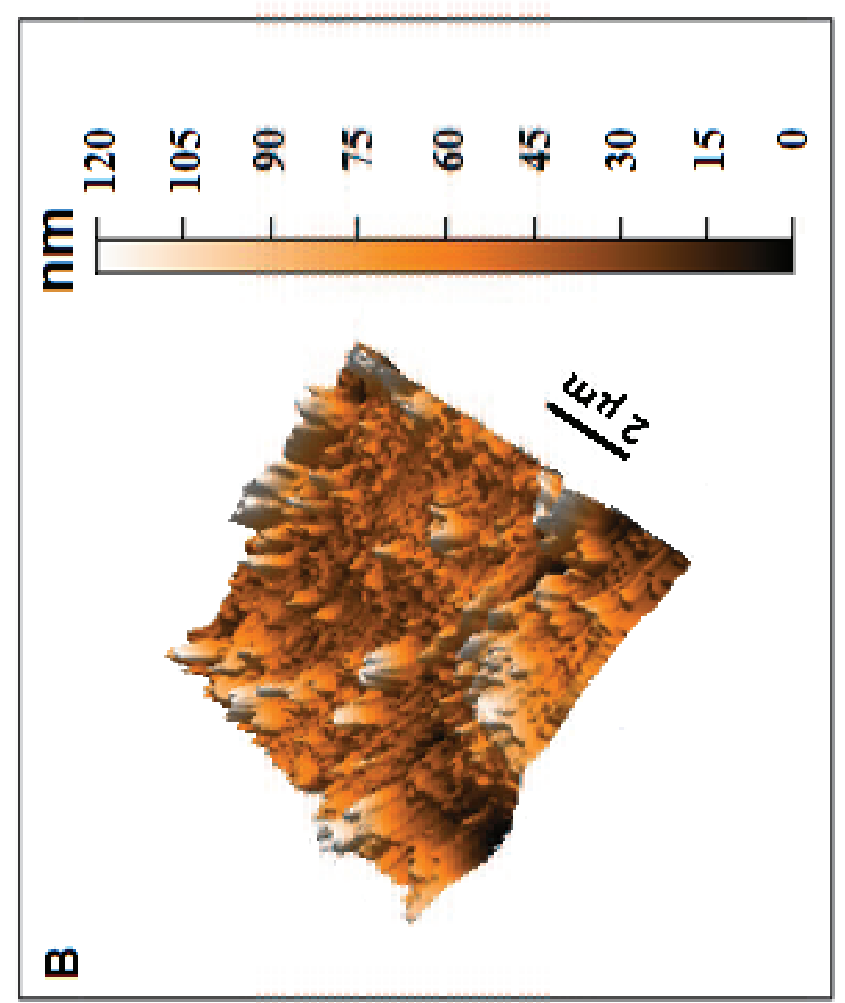

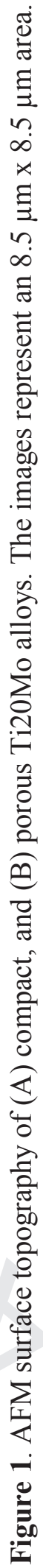




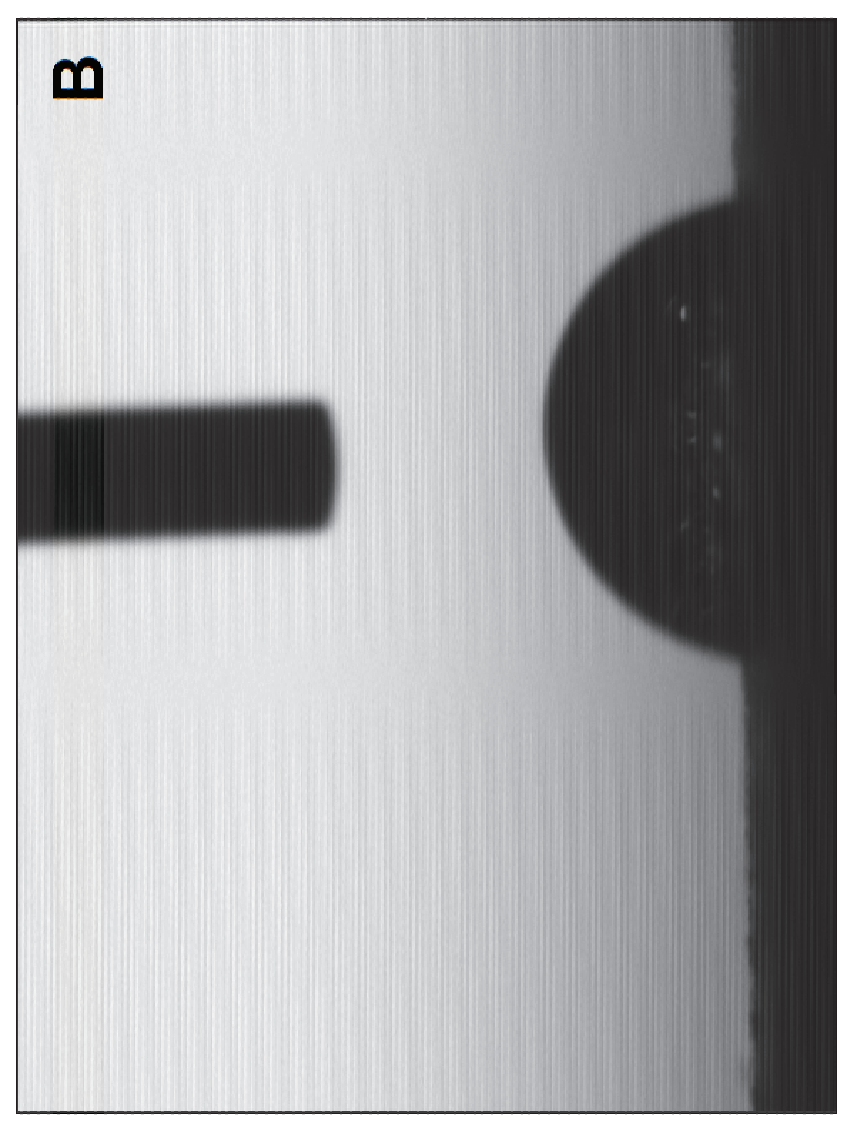

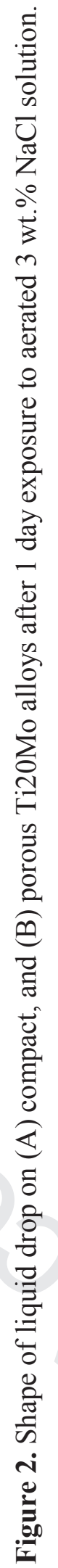



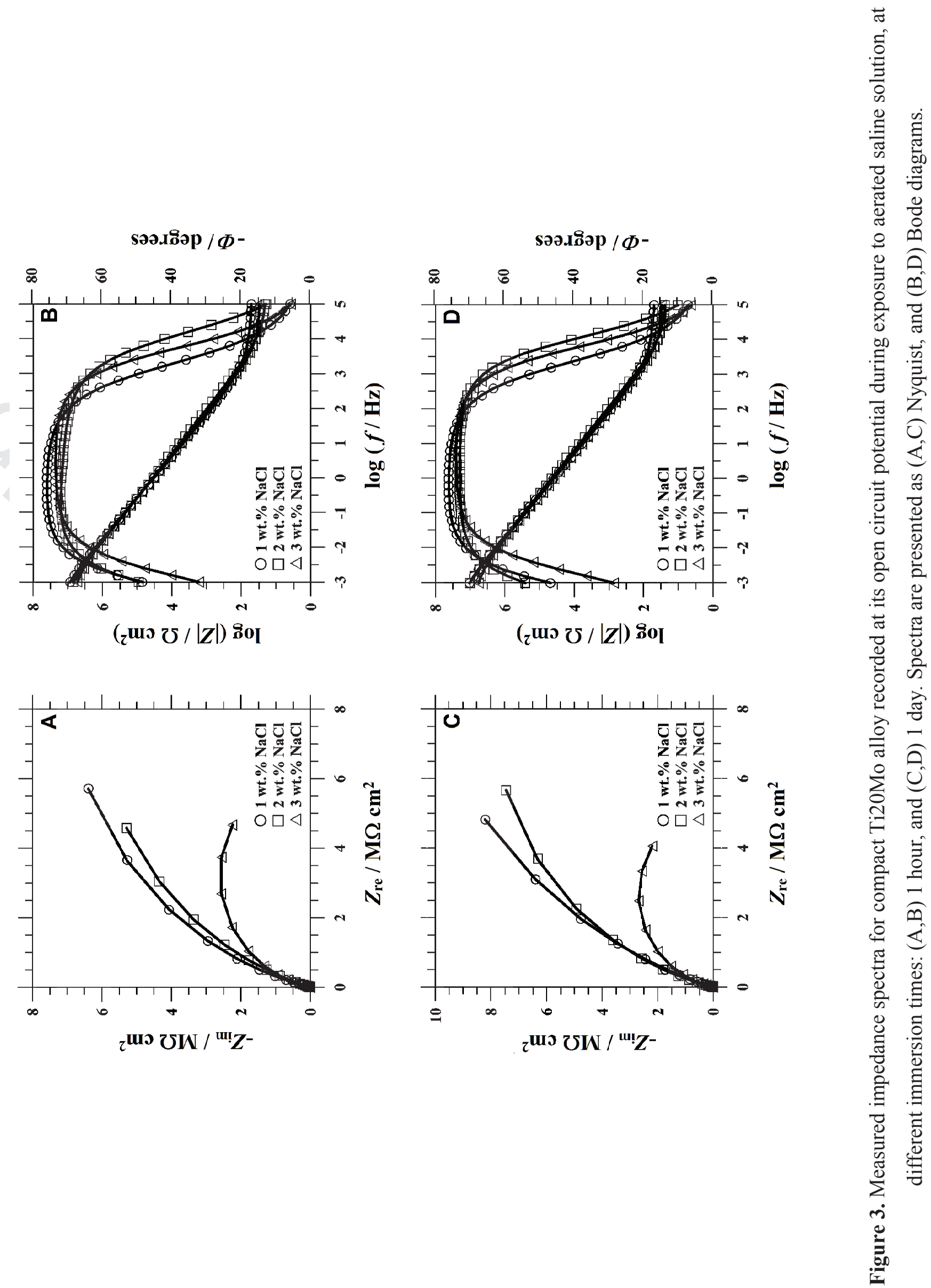
รวว.ภิวอ / $\Phi^{-}$
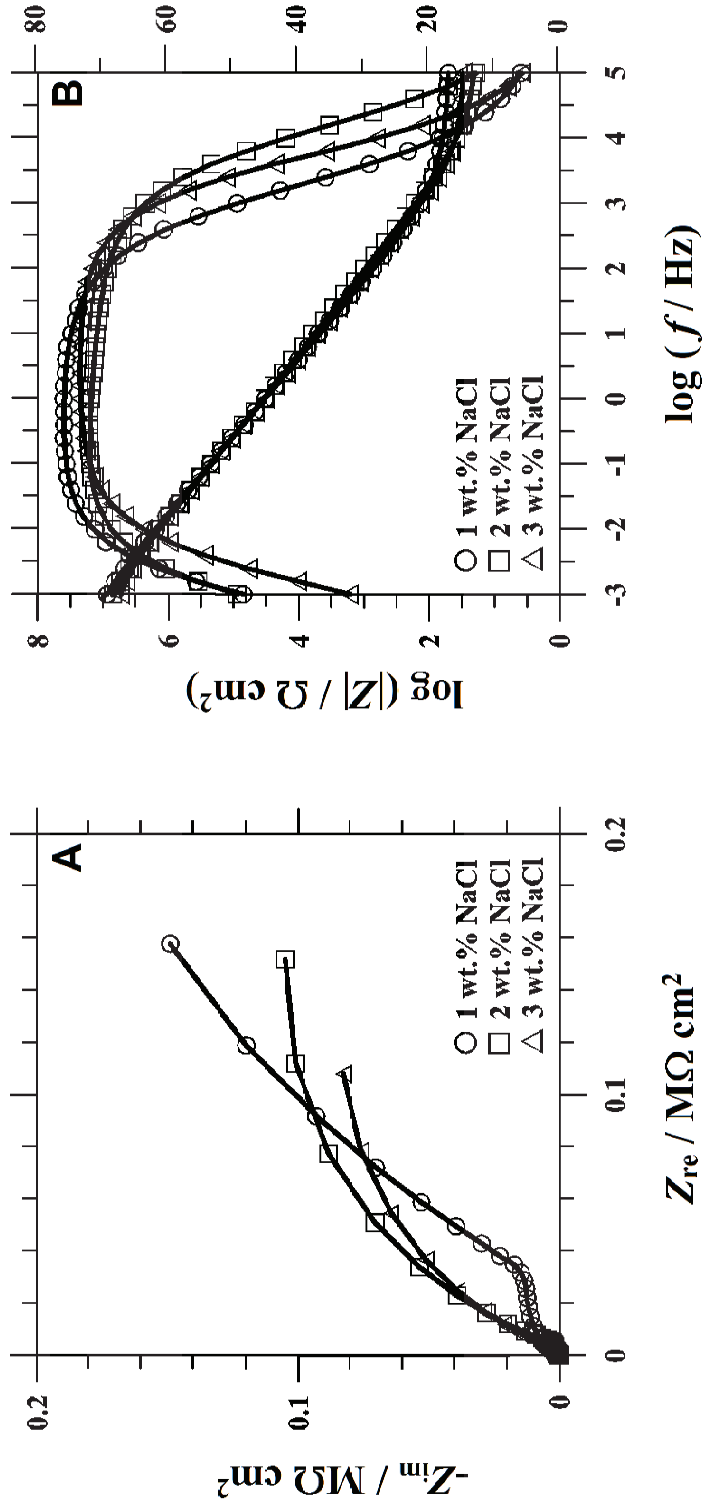

Sอวมถิวр / $\Phi$ -
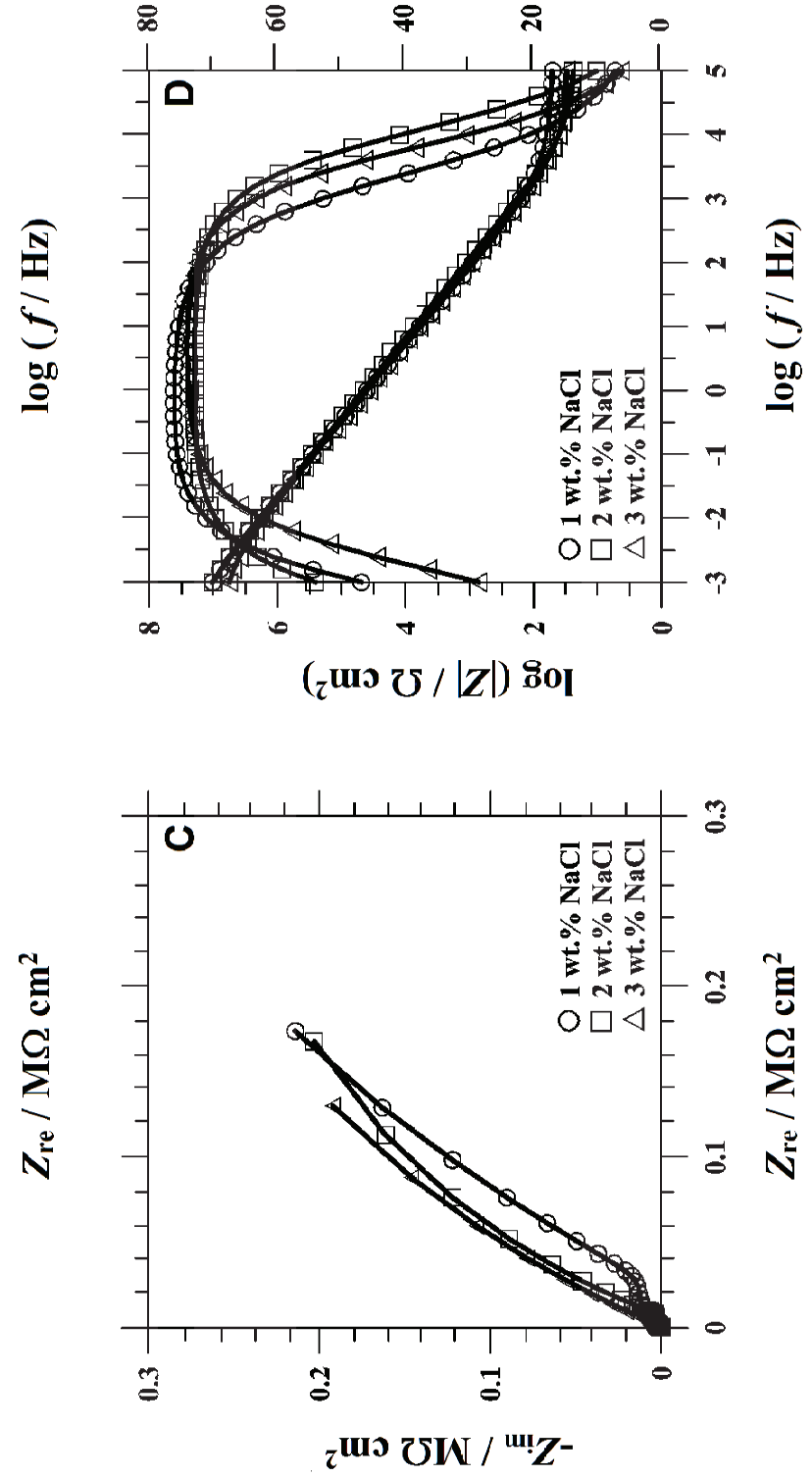

。ี

导

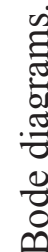

ㅇ

光 అ์

¿

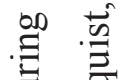

当

. 종

过

)

.”.

एี

告

䒕

융 क

흔

층 -

$\sum^{\circ}$

긍 들

응

ำ

\&

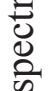

舟

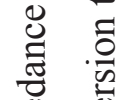

๕్․․

.

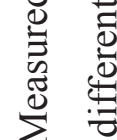

$\dot{\nabla}$

밀 
4

CD
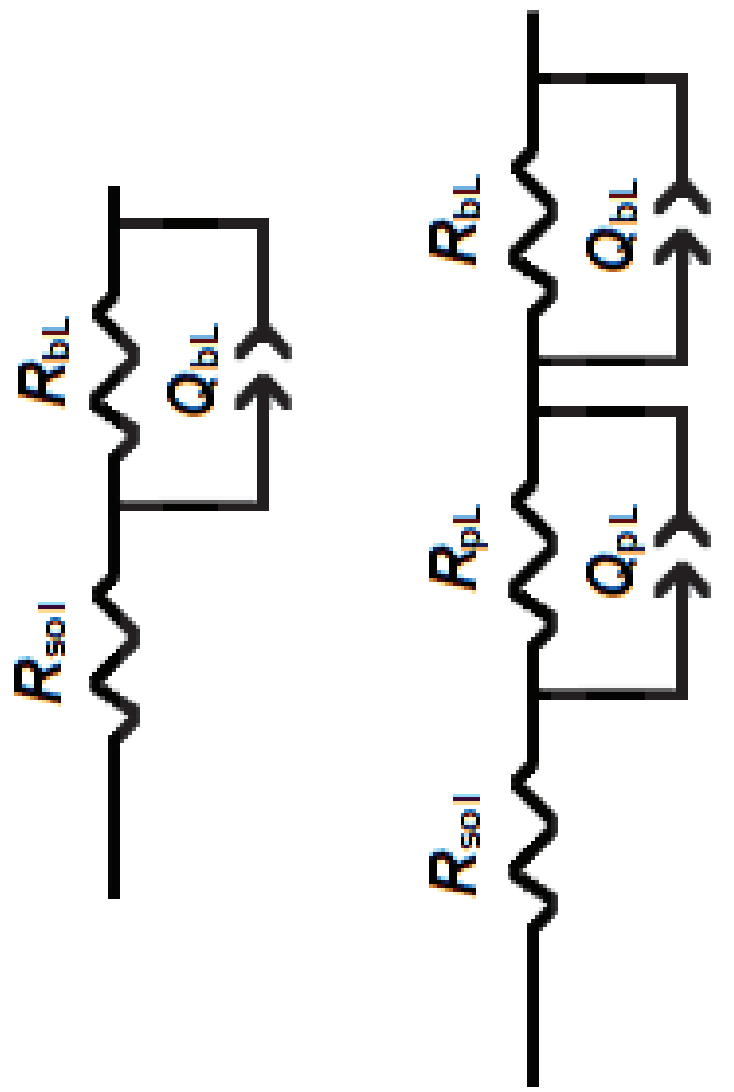

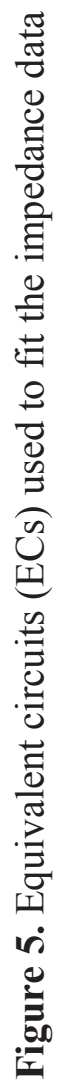



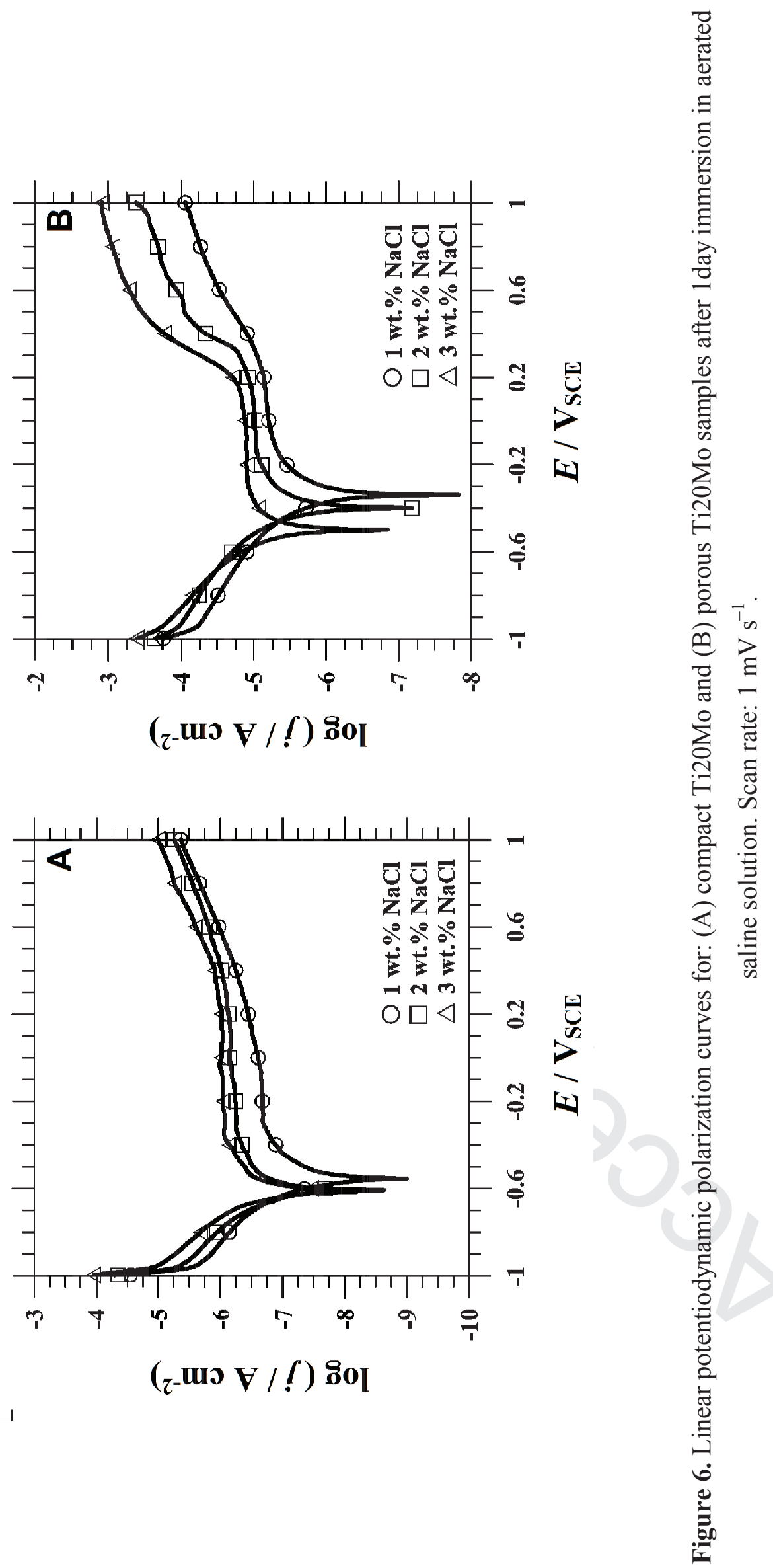

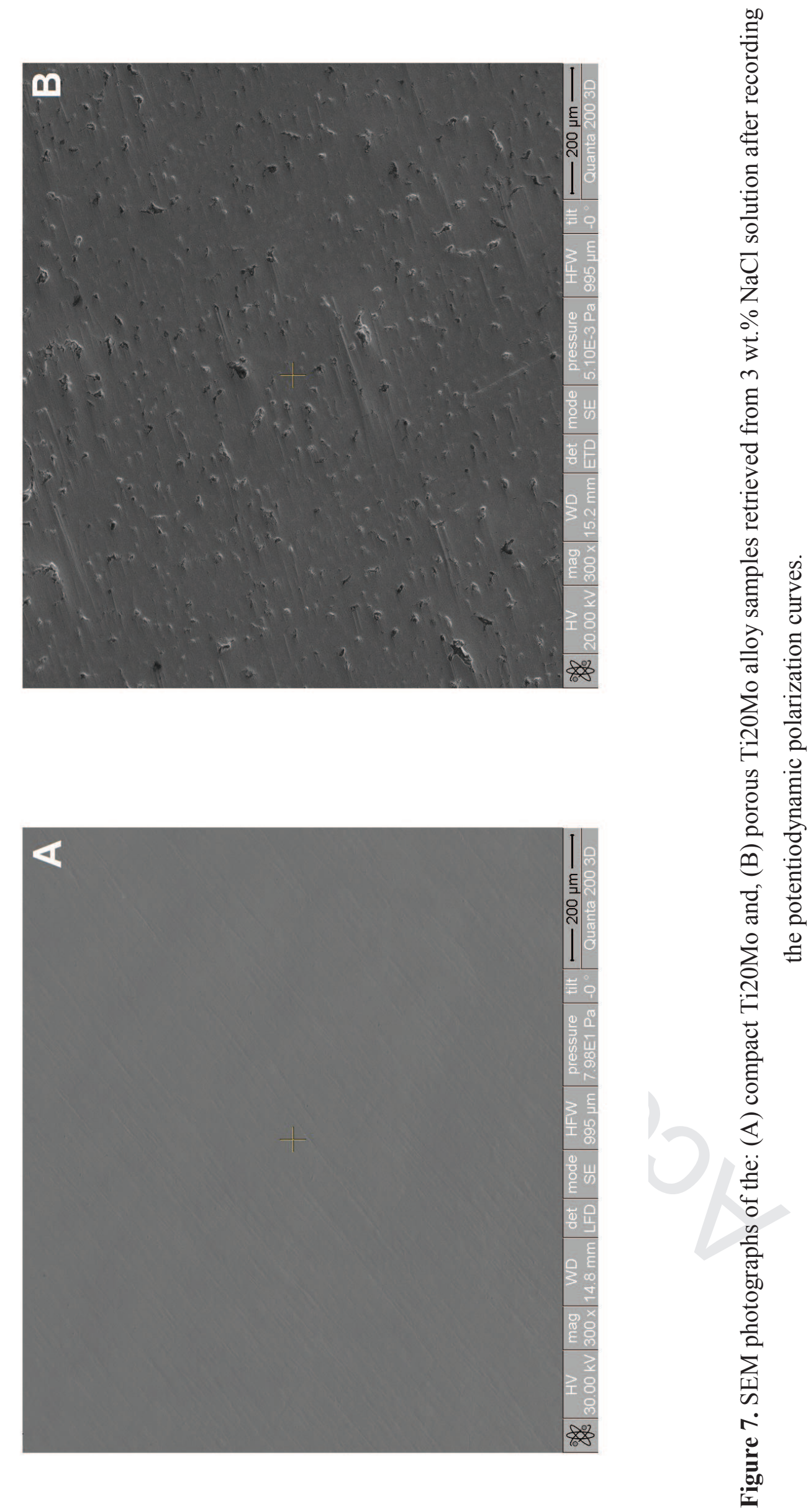


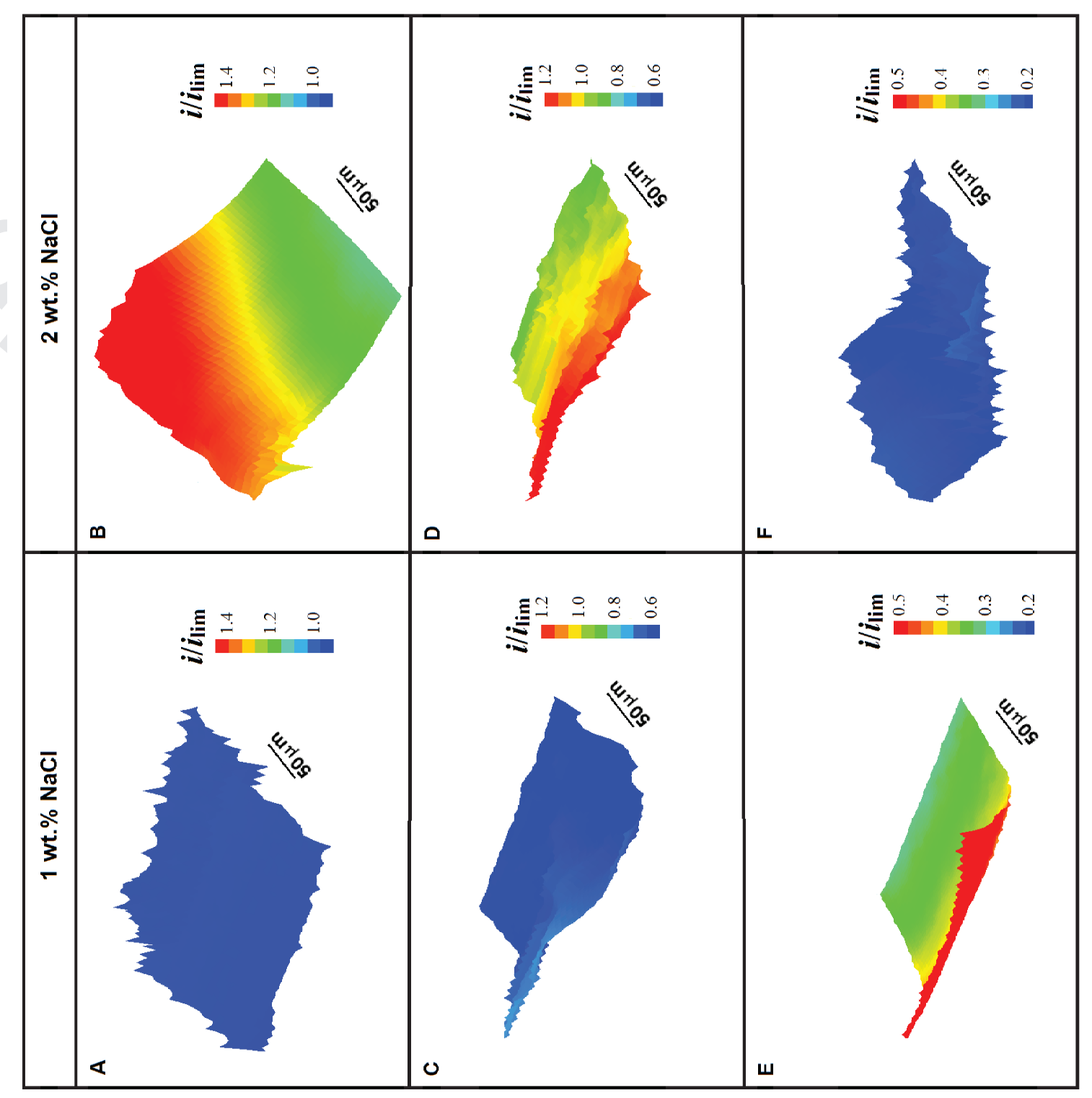

$\stackrel{\infty}{\Xi} \cong$

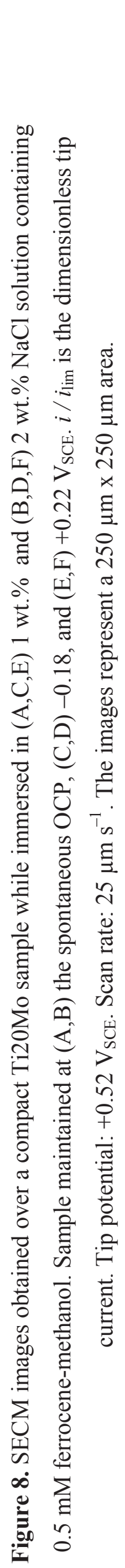



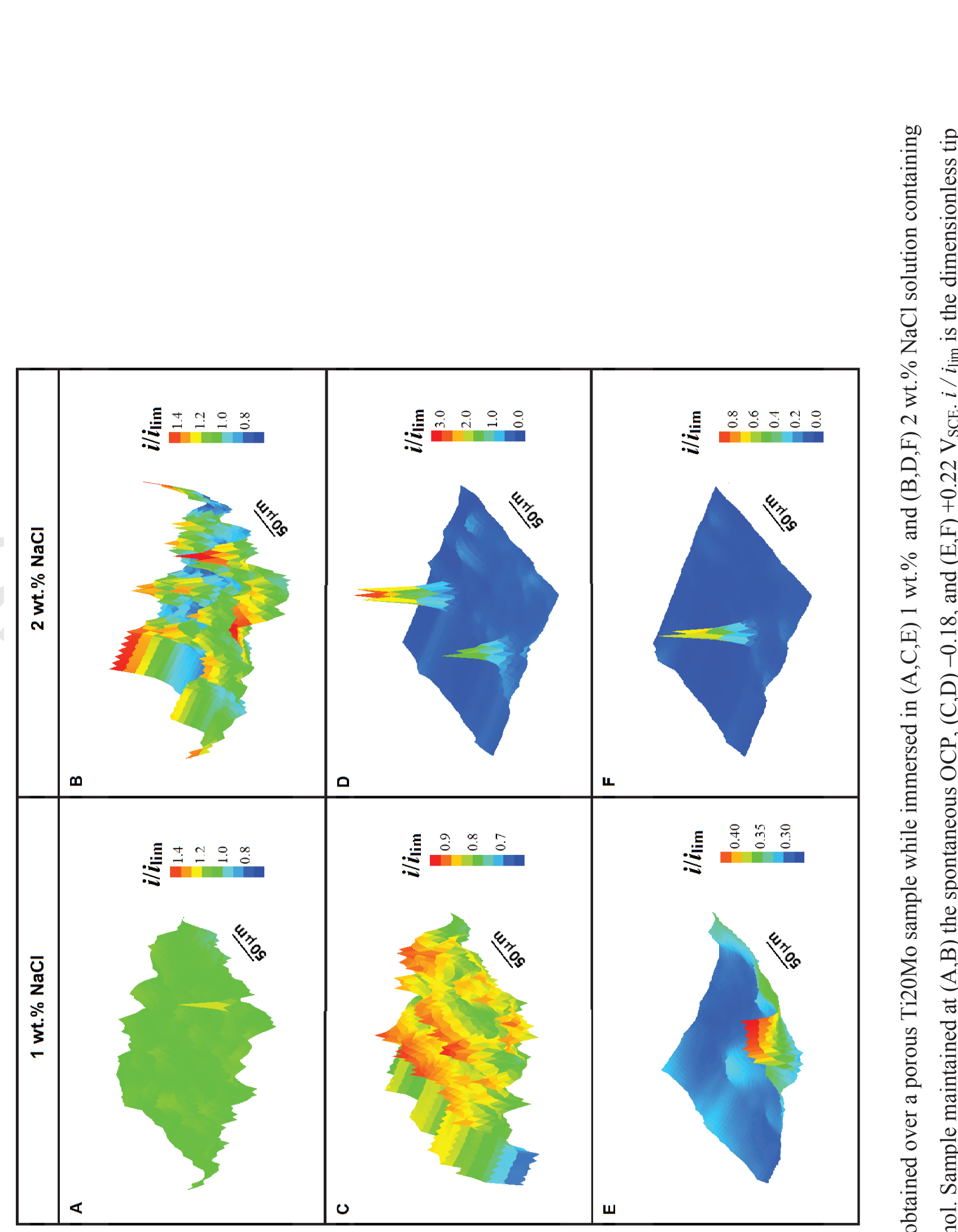

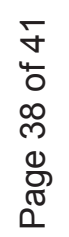

을

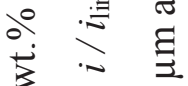

굘

I $>x$

คิ กิ

芯年 n

号 迁

(I)

U

过

记

总

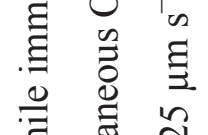

站 壳

雚 总

0 ก

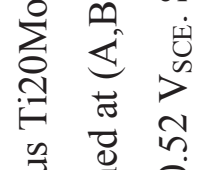

号

号 严

苛 节

ठ 을

苍 芯

券

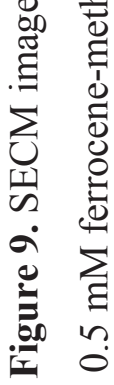




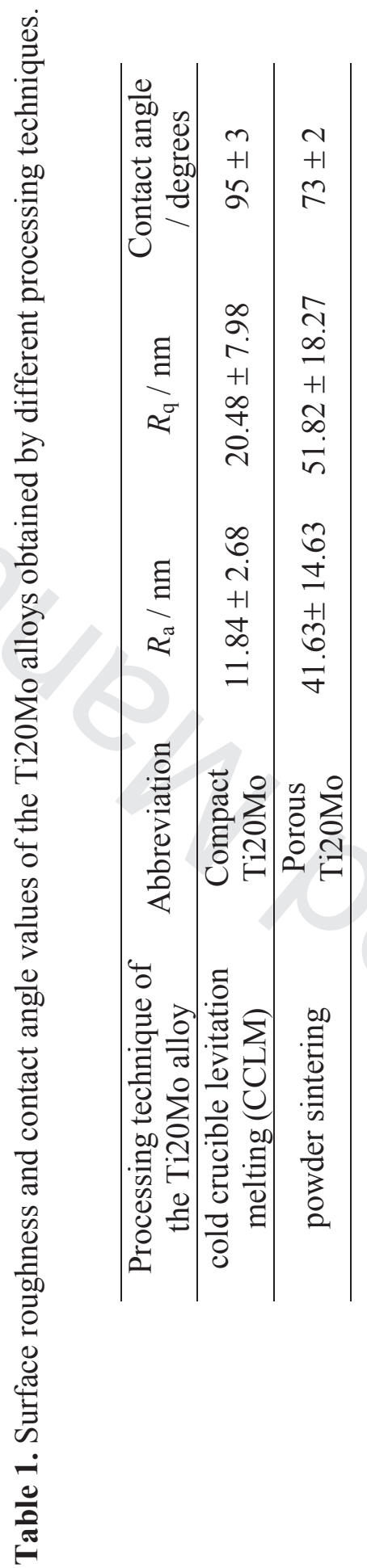




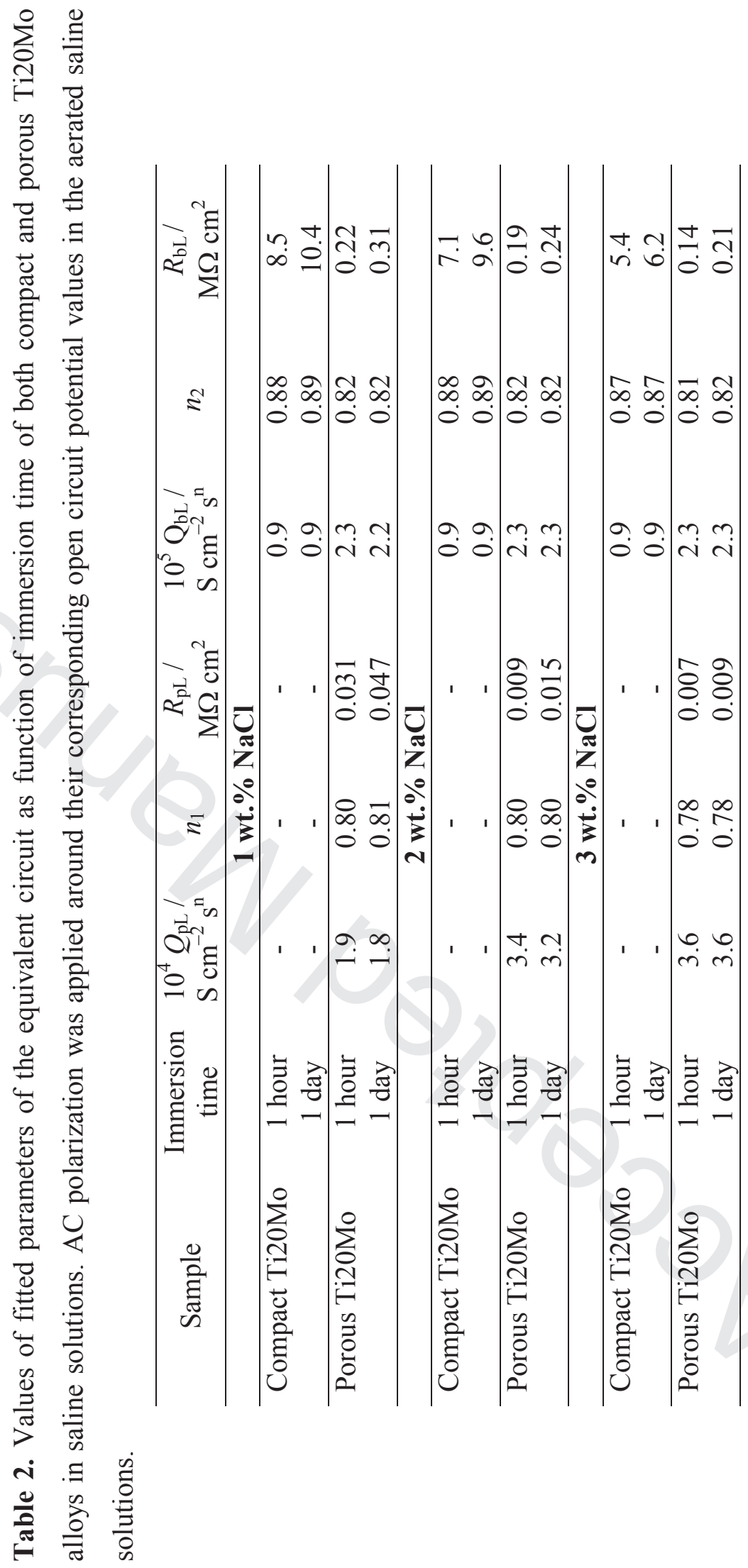


5

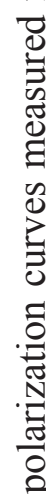

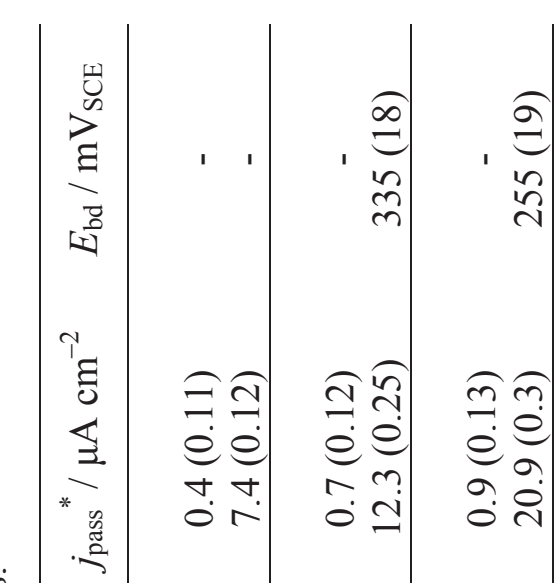

ֻี

可

ฮี๊

艺

(ิ)

.

क

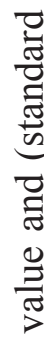

范

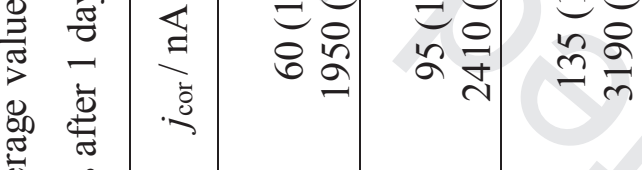

ণิ

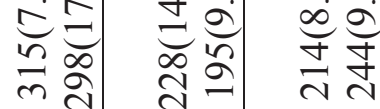

mवे तथ त

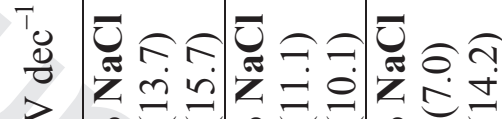

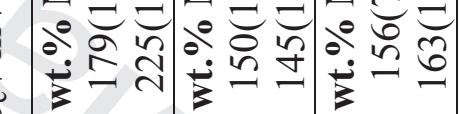

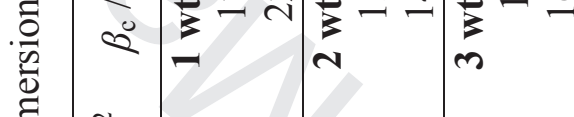

四

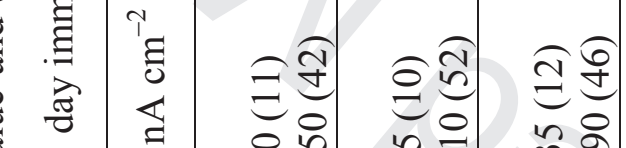

¿

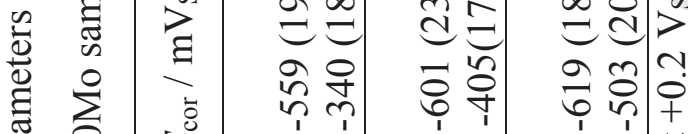

恶

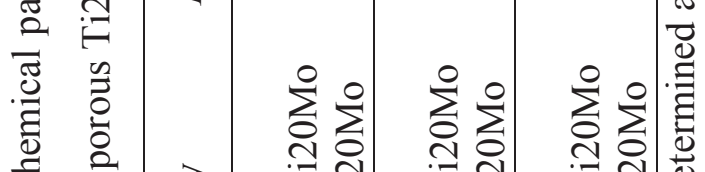

荡

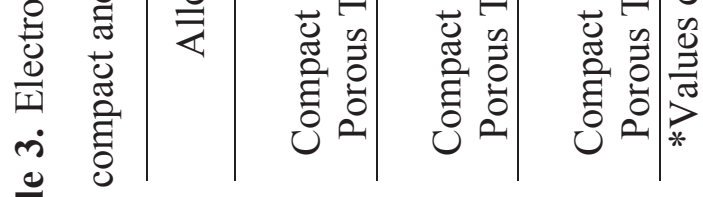

光 